\title{
Induction of Pulmonary Thromboembolism by Neutrophil Elastase in Collagen-Induced Arthritis Mice and Effect of Recombinant Human Soluble Thrombomodulin
}

\author{
Toshiaki Matsuoka $^{a}$ Enjing Jin ${ }^{a} \quad$ Akitoshi Tachihara $^{b}$ Mohammad Ghazizadeh ${ }^{a}$

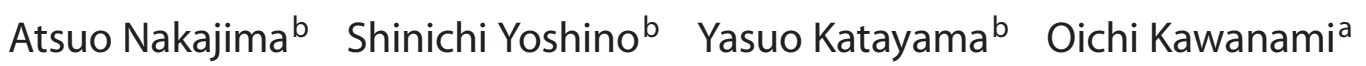 \\ a Department of Molecular Pathology, Institute of Development and Aging Sciences, Nippon Medical School, \\ Graduate School of Medicine, Kawasaki, and bepartment of Joint Disease and Rheumatism, Nippon Medical \\ School, Tokyo, Japan
}

\section{Key Words}

Collagen-induced arthritis $\cdot$ Thrombosis $\cdot$ Pulmonary

thromboembolism · Thrombin $\cdot$ Recombinant human soluble thrombomodulin

\begin{abstract}
We previously reported that during total knee arthroplasty in rheumatoid arthritis (RA) patients, the use of tourniquet might promote local release of neutrophil elastase (NE) from neutrophils, which may contribute to the development of pulmonary thromboembolism (PTE) and tissue injury. The aim of this study was to develop PTE by the use of NE in a mouse model of collagen-induced arthritis (CIA) and investigate the relationship between thrombus and endothelial cells as well as the effect of recombinant human soluble thrombomodulin (rhs-TM) in reducing the risk of PTE. Male DBA/1J mice were injected intracutaneously at several sites with an emulsion containing bovine collagen and later a booster shot to produce CIA mice. Subsequently, NE was injected intravenously 2 times a day for 3 days and after a further 4 days, mice were sacrificed. A group of mice received rhs-TM injections prior to NE injections. We divided the mice into four groups of normal, $\mathrm{ClA}$ control, $\mathrm{Cl}+\mathrm{NE}$, and $\mathrm{ClA}+$ rhs-TM + NE mice and evaluated thrombus formation status. All CIA + NE mice developed PTE. In contrast, no thrombosis
\end{abstract}

was found in normal control, CIA control and CIA + rhs-TM + NE mice. Plasma thrombin level, fibrinogen expression and neutrophil count were increased in $\mathrm{ClA}+\mathrm{NE}$ mice. Double staining for anticoagulant TM and procoagulant von Willebrand factor (VWF) in pulmonary endothelial cells in normal mice showed a TM-dominant expression while in both CIA control and $\mathrm{ClA}+\mathrm{NE}$ mice a vWF-dominant expression compatible with coagulant status was observed. Injection of rhsTM into CIA + NE mice resulted in a phenotypic conversion of endothelial cells from vWF-dominant to TM-dominant expression and a reduction in fibrinogen deposition. These findings demonstrate that by repeated use of NE in CIA mice, it is feasible to produce PTE and to study its pathogenesis and that rhs-TM reduces the risk of PTE. We suggest that in surgical operations of upper and lower extremities in RA patients, the use of a tourniquet should be avoided as it may trigger NE release.

Copyright $\odot 2008$ S. Karger AG, Basel

\section{Introduction}

Pulmonary thromboembolism (PTE) is an extremely common medical problem, occurring either alone or as a postoperative complication of several diseases. Particularly, PTE is a serious complication after total knee ar-

\section{KARGER}

Fax +41613061234 E-Mail karger@karger.ch www.karger.com
(C) 2008 S. Karger AG, Basel

$1015-2008 / 08 / 0755-0295 \$ 24.50 / 0$

Accessible online at:

www.karger.com/pat
Prof. Oichi Kawanami

Department of Molecular Pathology, Institute of Development and Aging Sciences

Nippon Medical School, Graduate School of Medicine

1-692 Kosugi-cho, Nakahara-ku, Kawasaki 211-8533 (Japan)

Tel. +81 44733 1823, Fax +81 44733 1293, E-Mail kawanami@nms.ac.jp 
throplasty (TKA) in orthopedic surgery, sometimes leading to patients' death. Clinically detected PTE occurs in $2-10 \%$ of patients with deep venous thrombosis who have had knee or hip arthroplasty and the incidence of fatal pulmonary embolism is $1-2 \%[1,2]$. Asymptomatic pulmonary embolism may occur in as many as $10 \%$ of patients $[1,3,4]$.

Recently, many researchers have studied the causes and treatments of PTE using different animal models. The methods of producing animal models of PTE are diverse $[5,6]$, for example, injections of thrombin and autologous blood clot embolization [3, 7], different types of knockout mice [5], bone marrow transplantation $[4,8]$, or vascular injury models by different chemicals. But all these animal models represented acute PTE, or in other words they were not organized thrombosis models. Commonly neutrophils, monocytes, and endothelial cells enter the thrombus as it is organized.

PTE may result from an imbalance between procoagulant, anticoagulant, and fibrinolytic activity. In this context, inflammation and hemostasis are coupled through common activation and regulatory systems. During inflammation, the hemostatic balance may be disturbed, resulting in the increased production of procoagulant factors and decreased regulation of anticoagulant responses. Thus, thrombosis promotes inflammation, which in turn stimulates a prothrombotic tendency.

Thrombomodulin (TM) is a potent anticoagulant protein expressed mainly on the surface of vascular endothelial cells and prevents blood clotting on the internal surface of vessels. Endothelial TM is a key component of the protein $\mathrm{C}$ anticoagulant pathway that facilitates the activation of protein $\mathrm{C}$ by thrombin [9]. Therefore, TM acts as an intrinsic anticoagulant barrier between the blood and the endothelium. The plasma level of TM is elevated in disseminated intravascular coagulation and atheromatous arterial disease $[5,10]$. Moreover, several studies have shown that reduced TM enhances thrombus formation $[11,12]$. Furthermore, recombinant human soluble TM (rhs-TM), a soluble derivative of human TM, has been developed and shown to bind directly to thrombin, showing a potent anticoagulant activity [13]. Previous studies have shown that rhs-TM acts as a potent anti-inflammatory molecule such as in endotoxin-induced tissue damage [14] and by inhibiting pulmonary accumulation of leukocytes through thrombin binding and the subsequent protein $\mathrm{C}$ activation [15] or by suppressing leukocyte/macrophage infiltration in the glomeruli in a rat model of thrombotic glomerulonephritis [16], and thus may have some effect on chemotaxis.
On the other hand, tissue factor (TF) is a cell surface protein that is expressed constitutively by monocytes, macrophages and fibroblasts $[17,18]$. The main function of TF is to form a complex with factor VII/VIIa that converts factors IX and $\mathrm{X}$ to their active forms. TF exposure is a potent prothrombotic trigger that initiates activation of both the intrinsic and extrinsic blood coagulation cascade [19]. TF is also involved in the pathophysiology of systemic inflammatory disorders, coagulopathies, and atherosclerotic disease [20]. Thus TF plays a pivotal role in the initiation of thrombotic complications.

We previously suggested that during TKA in rheumatoid arthritis (RA) patients, the use of a tourniquet might promote local release of neutrophil elastase (NE) from neutrophils, which can contribute to the development of PTE and tissue injury [21]. NE is a mediator derived from activated neutrophils and has a very strong tissue-damaging effect in spite of its original role in host defense [22-25]. Moreover, it is known that in RA patients, the general event is hypercoagulability based on inflammation status [26]. Thus we hypothesized that with repeated injections of NE in collagen-induced arthritis (CIA) mice, it will be feasible to develop thrombus formation and PTE. To test this hypothesis, we compared two groups of mice, one with and the other without CIA, in terms of thrombus formation. We could not verify thrombus formation in normal control and CIA control mice. Moreover, a single injection of NE was not sufficient to produce thrombus, as these mice did not show microvessel thrombi even 4 days after the last injection. This indicated that fibrinolysis events had been taken place. From our preliminary experimental data, we determined that $\mathrm{NE}$ injection of 2 times per day for 3 days was the most effective regimen to induce thrombus formation.

In the present study, we succeeded in generating organized thrombus and developing PTE in a mouse model of CIA and investigated the relationship between thrombus and endothelial cells as well as the effect of rhs-TM in reducing the risk of PTE in this model.

\section{Materials and Methods}

\section{Animals}

Male DBA/1J mice, 6 weeks old, were purchased from Saitama Experimental Animal Supply Co. (Saitama, Japan). The study protocol was approved by the Nippon Medical School Animal Care and Use Committee, and the care and handling of the animals were in accordance with the National Institutes of Health guideline. 


\section{Reagents}

Elastase (Athens Research \& Technology Inc., Athens, Ga., USA) was from human neutrophils with an activity of 20-22 units/mg protein. One unit is defined as the amount of enzyme that hydrolyzes $1 \mu \mathrm{mol}$ of Meo-suc-ala-ala-pro-val-pNA/min at $25^{\circ} \mathrm{C}$ in $100 \mathrm{mM}$ Tris- $\mathrm{HCl}, \mathrm{pH} 7.5$, with $500 \mathrm{~mm} \mathrm{NaCl}$. Elastase was used after dissolving in a buffer containing $50 \mathrm{mM}$ Na acetate, $\mathrm{pH} 5.5$, with $150 \mathrm{mM} \mathrm{NaCl}$ to be added to the salt-free lyophilized solid. rhs-TM was kindly provided by Asahi Chemical Industry (Tokyo, Japan); the method used for preparation of rhs-TM has been described previously [12].

\section{Collagen-Induced Arthritis}

Complete Freund's adjuvant (CFA) was prepared by grinding $100 \mathrm{mg}$ heat-killed Mycobacterium tuberculosis (H37Ra; Difco Laboratories, Detroit, Mich., USA) in $20 \mathrm{ml}$ incomplete Freund's adjuvant (Sigma Chemical Co., St. Louis, Mo., USA). An emulsion was formed dissolving $2 \mathrm{mg} / \mathrm{ml}$ bovine collagen (Gijyutsu Kenshukai Co., Tokyo, Japan) overnight at $4^{\circ} \mathrm{C}$ in $0.05 \mathrm{nM}$ acetic acid and combining it with an equal volume of CFA. CFA solution and the emulsion with CFA were always freshly prepared. Mice were injected intracutaneously at several sites into the base of the tail with a total of $100 \mu \mathrm{l}$ emulsion containing $100 \mu \mathrm{g}$ CFA and 250 $\mu \mathrm{g}$ M. tuberculosis. The same injection was repeated at day 21 ; however, due to toughening of the skin at the base of the tail, booster injections were proximal to the primary injection site. In experiments to test for the requirement for CFA, CFA was omitted from the emulsion of CFA [27-29].

\section{PTE Model}

Normal male DBA/1J mice $(\mathrm{n}=13)$ were injected intravenously with $\mathrm{Na}$ acetate buffer containing dissolved NE into the lateral tail vein 2 times a day for 3 days. After 4 days from the last injection, mice were sacrificed. CIA + NE mice $(n=28)$ were injected with NE ( $5 \mathrm{U} / \mathrm{kg}, 2$ times a day) into the tail vein for 3 days, and were sacrificed 4 days after the last injection. CIA + TM + NE mice $(n=13)$ were injected with rhs-TM $(1.5 \mathrm{mg} / \mathrm{kg}, 2$ times a day, $5 \mathrm{~min}$ before NE) and NE ( $5 \mathrm{U} / \mathrm{kg}, 2$ times a day) for 3 days, and were sacrificed 4 days after the last injection. These CIA model mice were injected with one more booster (collage type II and CFA). We induced hyperarthritis that is considered as hypercoagulability [30]. Overall, model groups consisted of normal mice $(n=10)$, CIA control mice $(n=10)$, CIA + NE mice $(n=28)$, and $\mathrm{CIA}+$ rhs-TM + NE mice $(\mathrm{n}=10)$.

\section{Surgical Procedure}

Mice (20-24 g) were anesthetized by intraperitoneal injection of $50 \mathrm{mg} / \mathrm{kg}$ sodium pentobarbital. After obtaining blood or bronchoalveolar lavage (BAL), fresh lung tissues were cut into pieces for different preparations. For example, frozen sections with brief fixation in $4 \%$ buffered paraformaldehyde were used for immunofluorescence staining, and fresh tissues with fixation in $4 \%$ buffered paraformaldehyde were used for paraffin embedding. For immunohistochemical studies, the frozen or paraffin sections reacted with primary antibodies as described below.

Thrombin-Antithrombin Complex III

To evaluate coaguability status, blood was collected from anesthetized mice by cardiac puncture and anticoagulated with $3.8 \%$ trisodium citrate (1:10 vol). Anticoagulated blood samples were centrifuged at 3,000 rpm for $5 \mathrm{~min}$ at $4^{\circ} \mathrm{C}$ and plasma samples stored at $-20^{\circ} \mathrm{C}$ until use. Thrombin-antithrombin III (TAT) complex concentration in plasma was measured by a commercially available sandwich enzyme immunoassay kit designed for human TAT, which also cross-reacts with murine TAT. Each new thrombin molecule formed in plasma will immediately be coupled to ATIII-TAT complexes and is measured as a surrogate for the circulating thrombin levels [31].

\section{BAL Fluid}

In brief, after intraperitoneal administration of pentobarbital sodium, an incision was made in the anterior neck, and a catheter was secured in the trachea with surgical suture. BAL was performed with $3 \mathrm{ml}$ of saline and 2-2.5 $\mathrm{ml}$ of lavage fluid was gently withdrawn. Cell differentiation of BAL was analyzed using a smear stained by the Wright-Giemsa method.

\section{Light Microscopy and Immunoperoxidase Staining}

Deparaffinized tissue sections were stained with hematoxylin and eosin for routine examination. Serial sections were stained by an avidin-biotin complex immunoperoxidase method [32-34]. The sections were treated with $0.3 \%$ hydrogen peroxidase for 30 min at $20^{\circ} \mathrm{C}$ to suppress endogenous peroxidase activity and incubated for $20 \mathrm{~min}$ in $10 \%$ normal goat serum to prevent nonspecific binding of the primary antibody. Incubation with the primary antibody for fibrinogen (1:600 rabbit polyclonal IgG; DAKO, Glostrup, Denmark) was performed overnight at $4^{\circ} \mathrm{C}$. The sections were reacted with 3,3'-diaminobenzidine (DAB) and counterstained with hematoxylin.

\section{Immunofluorescence Staining}

Fresh tissues were embedded in OCT compound, snap frozen in acetone dry ice, and stored at $-80^{\circ} \mathrm{C}$ until use. An indirect single or double immunofluorescence method was applied on 6 - $\mu \mathrm{m}$-thick sections as described previously [32-34]. Briefly, sections were incubated overnight at $4^{\circ} \mathrm{C}$ with either a combination of mouse monoclonal IgG and rabbit polyclonal IgG antibodies against TM (1:100; DAKO, Carpinteria, Calif., USA) or von Willebrand factor (vWF; 1:500; Glostrup, Denmark). After washing, the sections were incubated with fluorescein isothiocyanate (FITC)-labeled goat anti-rabbit IgG (Vector Laboratories, Burlingame, Calif., USA) for a single satin. For double staining, FITC-labeled goat anti-rabbit and Texas red-labeled horse antimouse IgG were applied as secondary antibodies for $60 \mathrm{~min}$ at room temperature in the dark. Nuclear counterstaining was done at room temperature with $0.01 \%$ TOTO-3 iodide (Molecular Probes, Eugene, Oreg., USA). The sections were evaluated by a confocal laser scanning microscope (model TC-SP, Leica, Heidelberg, Germany) equipped with argon and argon-krypton laser sources. In the resulting preparations, red fluorescence represented TM and green fluorescence showed vWF. Nuclei appeared as blue.

\section{Immunohistochemical Control Procedures}

Negative control preparations consisted of (1) omission of the primary antibody from the staining procedure and (2) substitution of corresponding amounts of normal immunoglobulin for the primary antibodies. Both control procedures consistently gave negative results. 


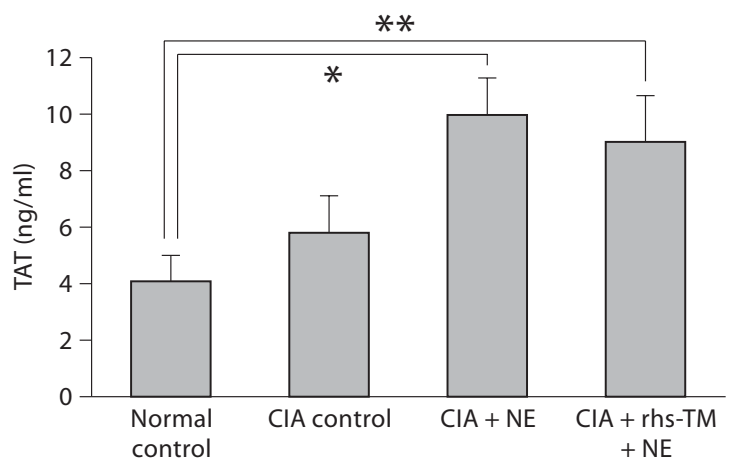

Fig. 1. Serum TAT complex levels. Enzyme immune assay for serum concentrations of TAT in mice shows significant increases in $\mathrm{CIA}+\mathrm{NE}$ and CIA + rhs-TM + NE mice as compared to the normal control. Data are expressed as mean \pm SEM of three independent measurements. ${ }^{*} \mathrm{p}<0.01 ;{ }^{* *} \mathrm{p}<0.05$.

\section{Semiquantitative Evaluation of Fibrinogen}

Each lung sample was fixed in $4 \%$ paraformaldehyde in phosphate-buffered saline, $\mathrm{pH} 7.4$, embedded in paraffin blocks, and serially sectioned at 3- to $4-\mu \mathrm{m}$ thickness. Tissue sections were deparaffinized, rehydrated, and stained for fibrinogen (1:600; DAKO, Carpinteria, Calif., USA) to complete the analysis of the histopathology [30]. The staining for fibrinogen was semiquantitated with the observer blinded to treatment, using a Nikon microscope (Tokyo, Japan) with a $\times 20$ objective lens. The fibrinogen stains excluding nuclear stains were assessed by the Scion image analysis system (Beta 4.02 for Windows, Frederick, Md., USA). We evaluated fibrinogen densities in 20 microscopic fields and compared the mean values in each group [35].

\section{Apoptosis and Proliferation Assessment}

A terminal deoxynucleotidyl transferase-mediated dUTP nick end labeling (TUNEL) assay that relied on DNA fragmentation, the hallmark of apoptosis, was used as a primary method to investigate apoptosis. Tissue sections were processed for the TUNEL. Briefly, sections were rehydrated through xylene and graded alcohols. Endogenous peroxidase activity was quenched in peroxide/ methanol prior to incubation for $30 \mathrm{~min}$ with proteinase $\mathrm{K}(10 \mu \mathrm{g} /$ $\mathrm{ml}$ in $10 \mathrm{mM}$ Tris/ $\mathrm{HCl}, \mathrm{pH} 7.6)$ at $37^{\circ} \mathrm{C}$. Sections were then incubated for $1 \mathrm{~h}$ with terminal deoxynucleotidyl transferase (Tdt; In Situ Cell Death Detection Kit, Roche Inc., Germany) which catalyzes the labeling of DNA strand breaks with deoxyuridine triphosphates. During this step, slides were coverslipped. After washing and subsequent incubation with antidigoxigenin peroxidase conjugate for $30 \mathrm{~min}$, slides were developed with DAB substrate, counterstained with methyl green, dehydrated, coverslipped, and then examined for evidence of apoptosis. We also investigated whether endothelial cell apoptosis was accompanied by a compensatory proliferative or reparative response. We selected Ki-67 immunohistochemical staining (rabbit polyclonal IgG, Abcam, Cambridge, UK, 1:25) as a marker for the cell proliferation.
Semiquantitative evaluation of TUNEL assay and Ki-67 staining were performed in each group. At first, each section was observed at $\times 200$ magnification, and then 20 middle $(40-100 \mu \mathrm{m}$ in diameter)- or small (10-40 $\mu \mathrm{m}$ in diameter)-sized vessels were randomly selected by three observers. Next, in each vessel positive endothelial cells were counted and a ratio was represented as the number of positive endothelial cells/vessel total endothelial cells according to a method described previously [36].

Immunohistochemical Staining for Caspase 3 (Active Form)

$\mathrm{ABC}$ immunostaining was applied to identify the active form of caspase 3 (rabbit polyclonal IgG, Abcam). The sections were pretreated with proteinase $\mathrm{K}(20 \mu \mathrm{g} / \mathrm{ml})$ for $30 \mathrm{~min}$ at $37^{\circ} \mathrm{C}$, and then endogenous peroxidase was inhibited as above. The primary antibody for caspase 3 was applied for $1 \mathrm{~h}$ at $37^{\circ} \mathrm{C}$. Biotin-labeled goat anti-rabbit IgG was applied as the secondary antibody and the chromogenic reaction was evaluated by DAB. Semiquantitative evaluation was done as described above.

\section{Statistical Analysis}

All values were expressed as mean \pm SEM. Significance was determined by a Mann-Whitney's U test to determine differences among groups. These tests were performed using SPSS statistical software, and $\mathrm{p}<0.05$ was considered significant.

\section{Results}

\section{Development of Thrombosis}

In all CIA + NE mice $(n=28)$ thromboemboli were observed in the lung which was partly organized thrombosis surrounded by endothelial cells. Formation of fibrin-rich thromboemboli was distributed in small (10$40 \mu \mathrm{m})$ - and medium (40-100 $\mu \mathrm{m}$ )-size microvessels in the lung. On the other hand, in normal mice $(n=10)$, CIA control mice $(\mathrm{n}=10)$, and CIA + rhs-TM + NE mice $(\mathrm{n}=$ 10) no thrombosis was found.

\section{Evaluation of TAT Complex Levels}

Each new thrombin molecule formed in plasma will immediately be coupled to ATIII-TAT complexes which were measured as a surrogate for the circulating thrombin levels. We compared the plasma TAT level of the normal mice group with other CIA mice groups (fig. 1). There were significant increases in plasma TAT levels in $\mathrm{CIA}+\mathrm{NE}$ and CIA + rhs-TM + NE mice versus normal mice $(9.998 \pm 1.297$ and $9.038 \pm 1.553$ vs. $4.150 \pm 0.832$ $\mathrm{ng} / \mathrm{ml} ; \mathrm{p}<0.01$ and $\mathrm{p}<0.05$, respectively). CIA control mice also showed an increase. There was no statistically significant difference between the CIA + NE group and the CIA + rhs-TM + NE group. However, CIA + rhs-TM + NE mice did not show pulmonary embolism or fibrin deposition in the lung despite a high level of serum TAT. 

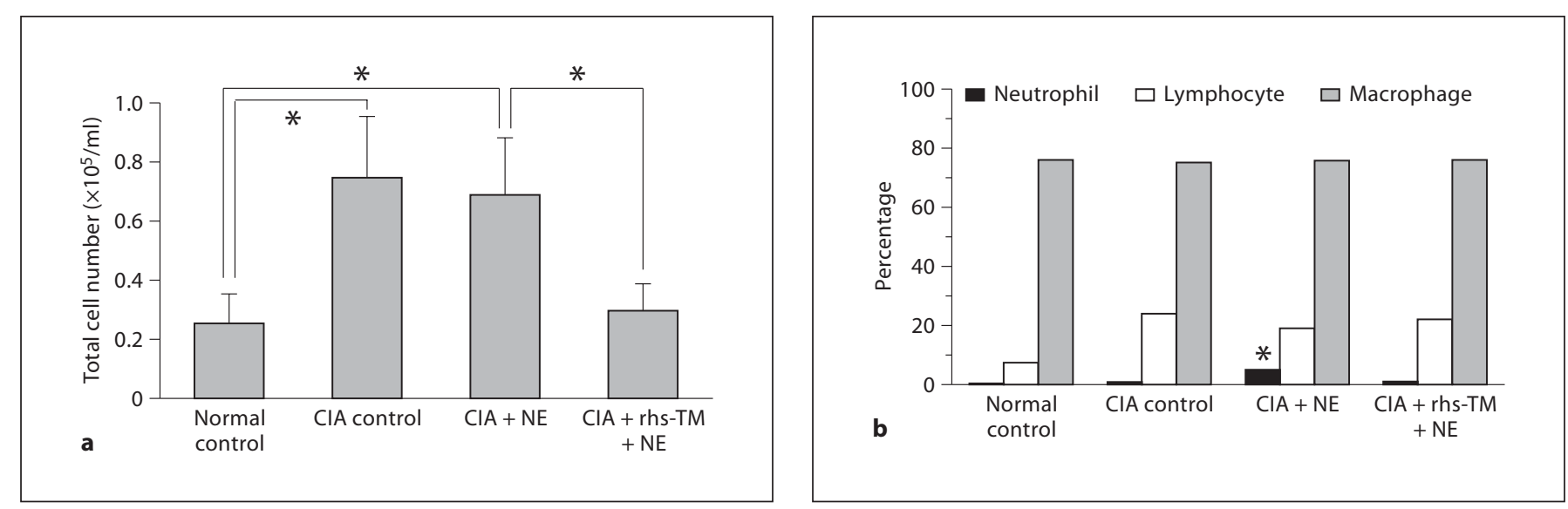

Fig. 2. Evaluation of BAL fluids. a Total cell number in BAL from CIA control and CIA + NE mice increased significantly as compared to normal control mice $\left({ }^{*} \mathrm{p}<0.05\right)$ and administration of rhs-TM could decrease the total cell number. $\mathbf{b}$ Differential cell count in BAL showed significantly increased neutrophils in CIA + NE mice $\left({ }^{*} \mathrm{p}<0.05\right)$, increase in lymphocytes in all CIA mice groups and no change in macrophage counts.

\section{Evaluation of BAL Fluids}

Total cell number in BAL was increased significantly in CIA control and CIA + NE mice $(\mathrm{p}<0.05)$ but not in $\mathrm{CIA}+$ rhs-TM + NE mice (fig. 2a). Cell differential counts showed a significantly increased neutrophil count in $\mathrm{CIA}+\mathrm{NE}$ mice compared to the other groups $(\mathrm{p}<0.05)$, and no change in macrophage counts (fig. 2b). Lymphocyte counts were increased in all CIA mice groups compared to the normal control group. As BAL in RA patients usually show increased lymphocytes, CIA mice in general simulated the same pulmonary internal environment. Moreover, multiple injections of NE intravenously affected endothelium and epithelium (alveolar cells) and interalveolar cells; therefore, total cell number and neutrophil count were increased in BAL from CIA + NE mice. Treatment with rhs-TM could reduce injuries exerted by NE administrations, as neutrophils in BAL from $\mathrm{CIA}+$ rhs-TM + NE mice were not increased (fig. 2b).

\section{Immunohistochemical and Confocal Microscopic \\ Observations}

Hematoxylin and eosin stains showed organized thrombosis surrounded by endothelial cells in CIA $+\mathrm{NE}$ mice.

Immunohistochemical examination for fibrinogen in CIA + NE mice $(n=28)$ at 4 days from the last injection showed many microthrombi composed of platelet aggregates and fibrin and thrombi in vessels $(>40 \mu \mathrm{m}$ in diameter) in all 28 mice. CIA control mice showed a slight exudation of fibrin in alveolar microvessels. CIA +
rhs-TM + NE mice $(n=10)$ did not show thrombus formation and fibrin exudation (fig. 3).

A coagulatory protein, vWF or factor VIII-related antigen is considered as one of the biological markers of endothelial cells, and is stored in the cytoplasmic inclusions (Weibel-Palade bodies) of endothelial cells. In contrast, TM which is an anticoagulant protein is expressed along the endothelial cell plasma membrane and plays a pivotal role in maintaining physiological functions of the endothelial cells in balance with procoagulant vWF protein. Confocal laser scanning immunofluorescence microscopy demonstrated a positive reaction for TM apparently in both luminal and abluminal plasma membranes of alveolar capillary endothelium in normal mice (fig. 4a). A group of microvessels ( $>10 \mu \mathrm{m}$ in diameter) in connective tissue, including vasa vasorum of large vessels, arterioles (of the pulmonary circulation), and venules of the bronchial circulation, was exclusively reactive for vWF in CIA mice (fig. 4b), but mostly nonreactive for TM similar to that in human lung. TM expression of endothelial cells appeared to be suppressed by NE injections in CIA mice (fig. 4c) while vWF expression especially in the juxta-alveolar zone was increased. CIA + NE mice treated with rhs-TM slightly lost TM expression and did not show increased vWF expression (fig. 4d).

\section{Semiquantitative Evaluation of Fibrinogen}

Fibrinogen intensity measurements showed that CIA control and CIA + NE mice had increased fibrinogen and the increase in fibrinogen in CIA + NE mice was more 


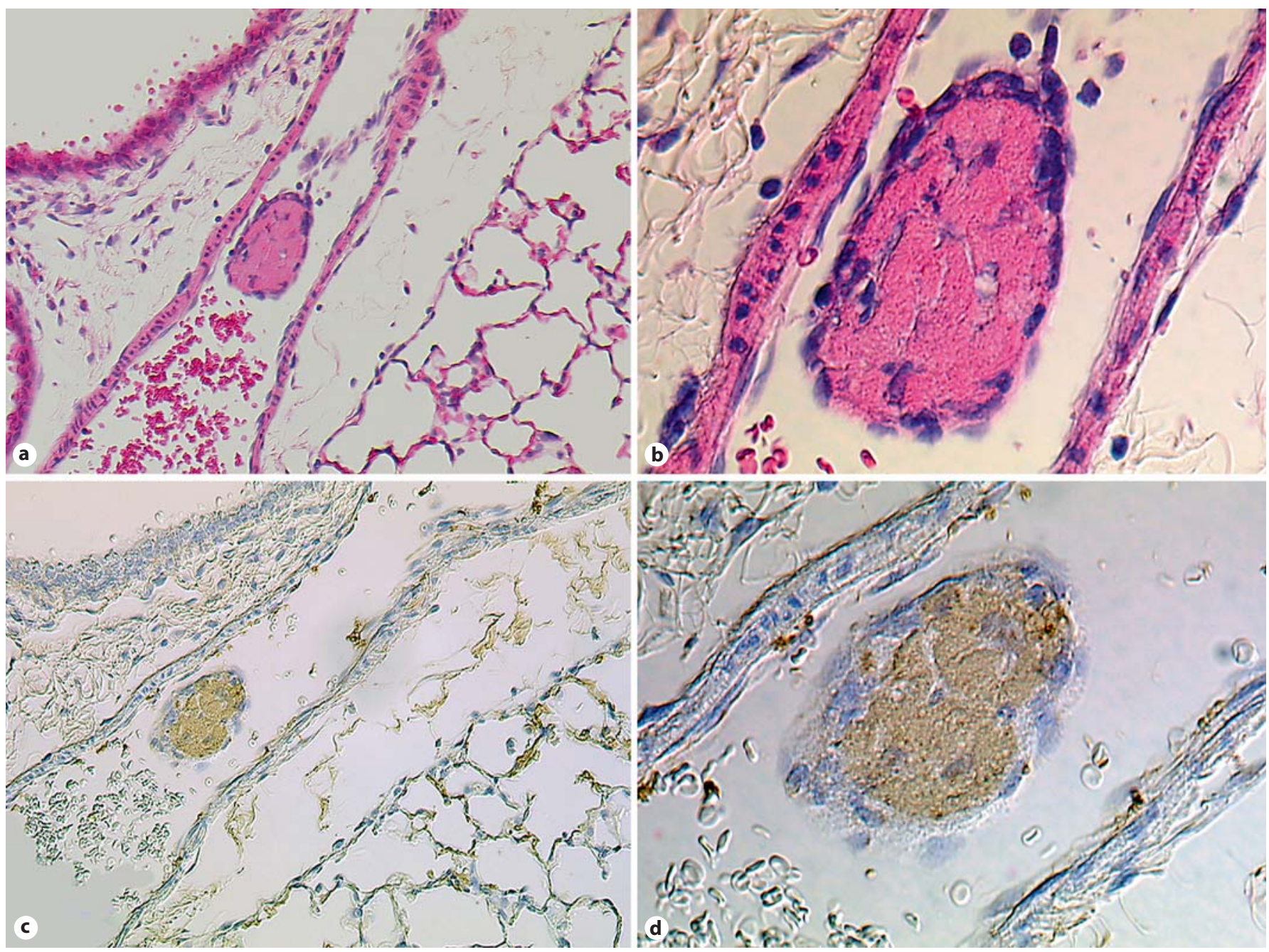

Fig. 3. Immunohistochemical observations. Organized thrombosis developed in lung from CIA + NE mice. Hematoxylin and eosin-stained section (a) and comparative fibrinogen-stained section (c) showing a thrombus surrounded by endothelium. b, d Higher magnifications. Original magnifications: $\times 200(\mathbf{a}, \mathbf{c})$ and $\times 400(\mathbf{b}, \mathbf{d})$.

than that in CIA control mice $(\mathrm{p}<0.05)$ (fig. 5). In addition, administration of rhs-TM revealed reduced fibrinogen depositions. The rationale for these events may be that inflammation itself renders coagulate dominant status and repeated administration of $\mathrm{NE}$ adds to this by causing fibrin deposition and thrombosis.

\section{Evaluation of Apoptosis and Proliferation in}

Endothelial Cells in Vessels

In TUNEL stains, positive endothelial cells in vessels were more increased in CIA control and CIA + NE mice than normal mice $(\mathrm{p}<0.01)$. On the other hand, administration of rhs-TM could reduce apoptosis $(\mathrm{p}<0.05)$ (fig. 6). In caspase-3 stains, we could observe significant differences between normal mice and CIA + NE mice (fig. 7). But among other groups, although caspase-3 staining markedly decreased in CIA + rhs-TM + NE mice, there were no significant differences which could be attributed to the differences in the methodology. Staining for Ki-67 cell proliferation marker was similar with apoptosis staining as mentioned above. Ki-67-positive endothelial cells were increased in CIA control and CIA $+\mathrm{NE}$ mice as compared to normal mice but not in CIA + rhs-TM + NE mice (fig. 8). These results show that endothelial cells injured by inflammation and NE were committing apoptosis and many Ki-67-positive cells were generated to preserve homeostasis. 

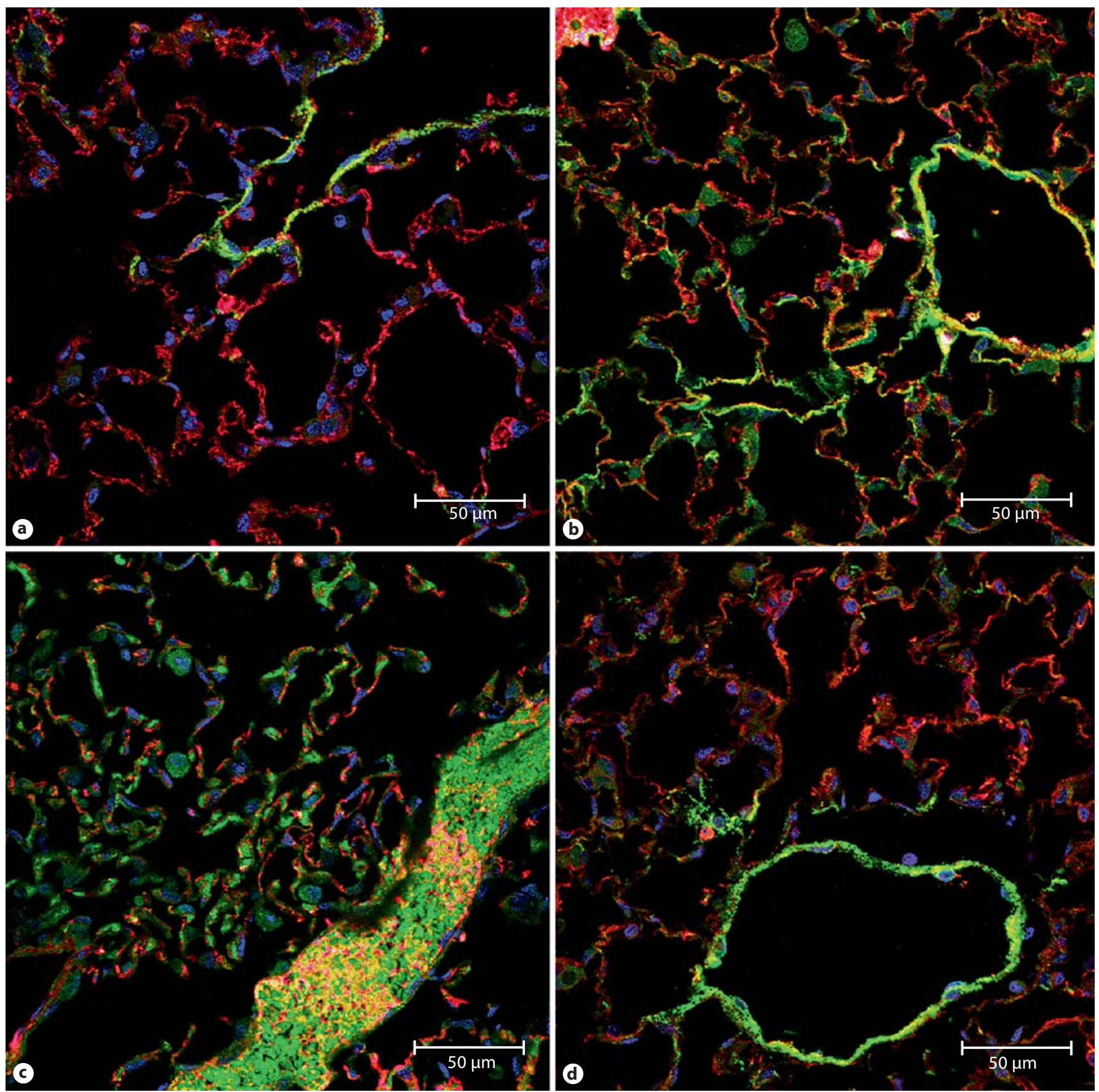

Fig. 4. Confocal microscopic observations. Confocal laser scanning immunofluorescence microscopy shows a positive reaction for TM apparently in both luminal and abluminal plasma membranes of alveolar capillary endothelium in normal mice (a). A group of microvessels ( $>10 \mu \mathrm{m}$ in diameter) in connective tissue, including vasa vasorum of large vessels, arterioles (of the pulmonary circulation), and venules of the bronchial circulation, was exclusively reactive for vWF in CIA mice (b), but mostly unreactive for TM similar to the human lung. TM expression of endothelial cells was suppressed in CIA/NE mice (c) while vWF expression especially in the juxta-alveolar zone was increased. In CIA + rhs-TM + NE mice (d) TM expression was slightly lost and vWF expression did not increase. 
Fig. 5. Semiquantitative evaluation of fibrinogen. Assessment of fibrinogen level shows a significant increase in CIA + NE mice compared to CIA control mice, which was suppressed in CIA + rhs-TM + NE mice indicating the effectiveness of rhs-TM administration. Data are expressed as mean \pm SEM of three independent measurements. ${ }^{*} \mathrm{p}<0.05$
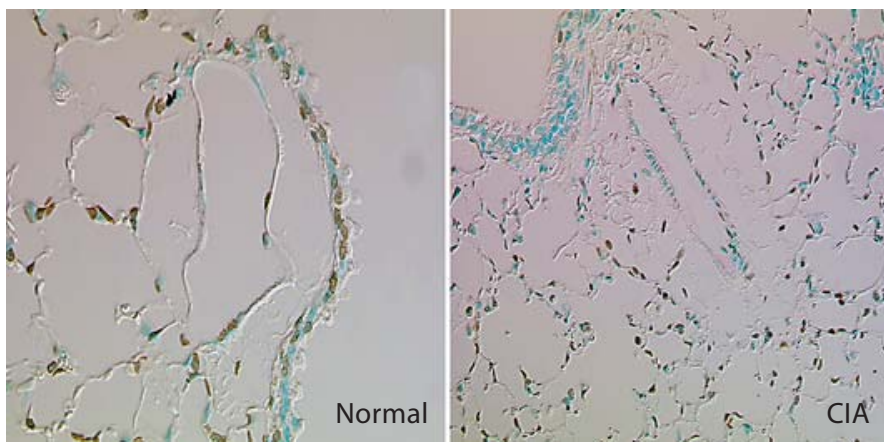

Fig. 6. Evaluation of apoptosis by the TUNEL method. a TUNEL staining for apoptosis cells in the lungs from different groups of mice. Original magnification: $\times 200$. b Endothelial cell $(E C)$ apoptosis was markedly increased in CIA control and CIA + NE mice and was suppressed in CIA + rhs-TM + NE mice showing the effectiveness of rhs-TM administration. Data are expressed as mean \pm SEM. ${ }^{*} \mathrm{p}<0.01 ;{ }^{*} \mathrm{p}<0.05$.

\section{Discussion}

In the present study, we succeeded in generating thrombus by repeated use of NE in a model of CIA mice that subsequently developed PTE. Previously we demonstrated that during TKA, the use of a tourniquet increased the NE level 8-fold and suggested that this event may promote the risk of developing PTE, particularly in RA patients $[21,37]$. On the other hand, the absence of PTE has been associated with a general status of decline in hyper-
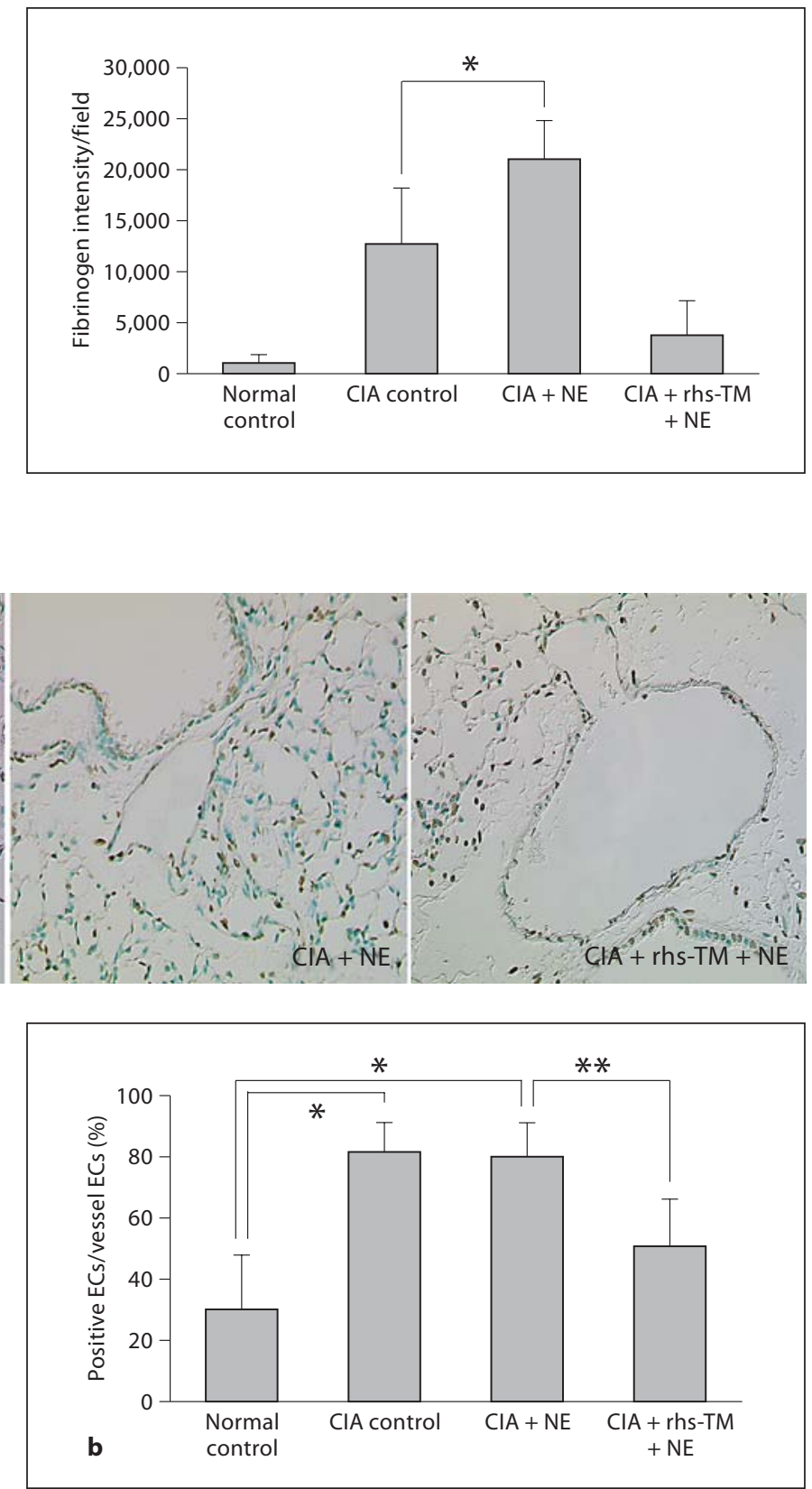

coagulability $[26,37]$. We attributed this to the so-called 'reperfusion injury', that is to say the release of NE by deflating tourniquet was the most important factor $[25,38]$. Therefore, we focused our attention on the role of NE in promoting PTE.

$\mathrm{NE}$ is known as a cause of acute lung injury and is the most destructive enzyme. It possesses various activities including, for example, degradation of almost all extracellular matrix and key plasma proteins, degradation of various cytokines such as proinflammatory cytokines 

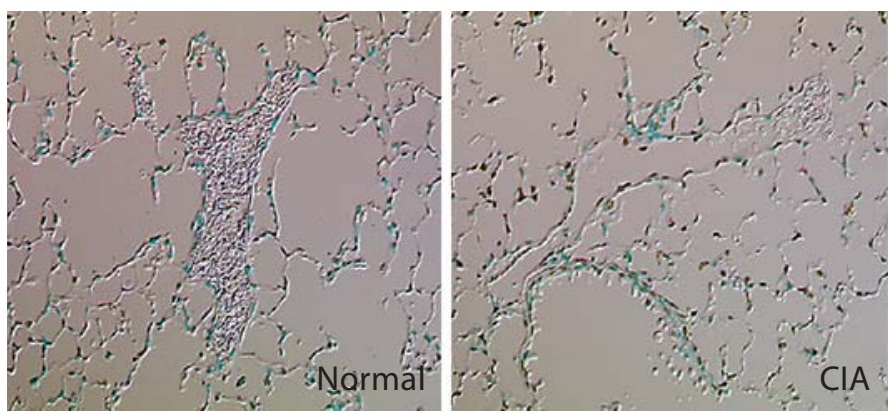
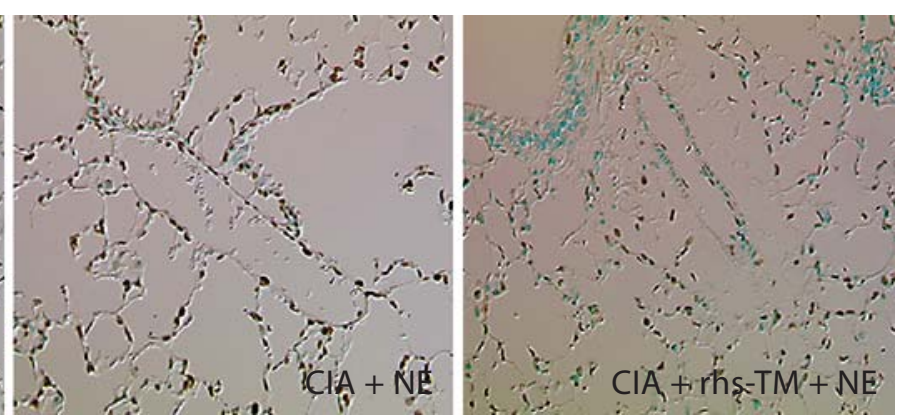

Fig. 7. Evaluation of apoptosis by caspase staining. a Caspase-3 (active form) staining for apoptosis cells in the lungs from different groups of mice. Original magnification: $\times 200$. b Endothelial cell (EC) apoptosis was markedly increased in CIA + NE mice but not in CIA + rhs-TM + NE mice showing the effectiveness of rhs-TM administration. Data are expressed as mean \pm SEM. ${ }^{*} \mathrm{p}<0.05$.

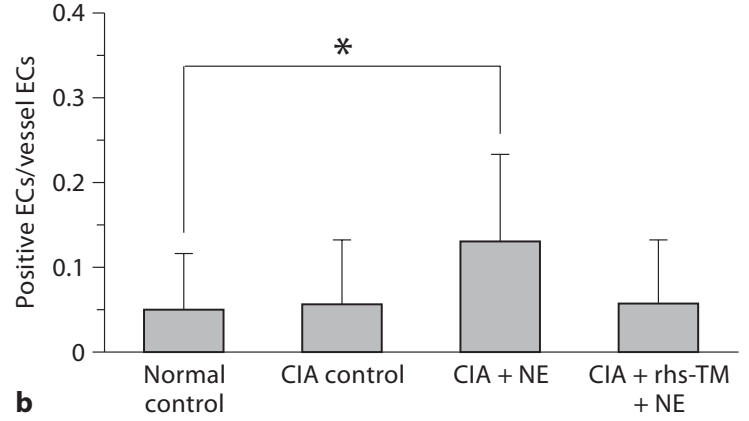

b control

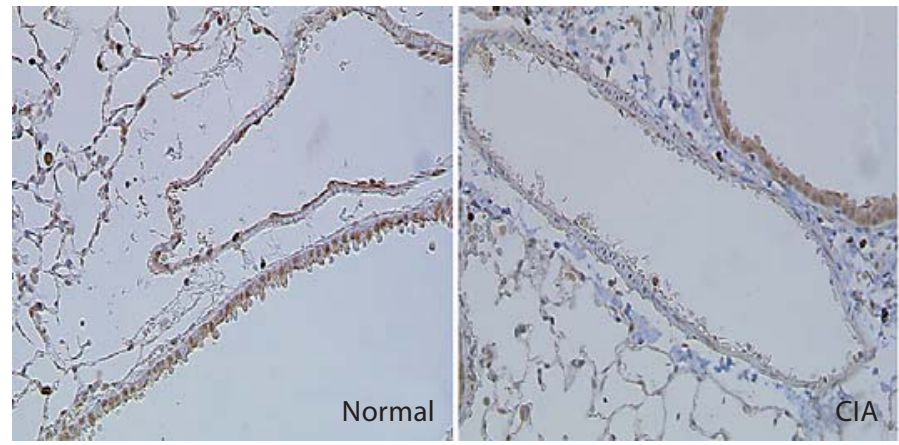

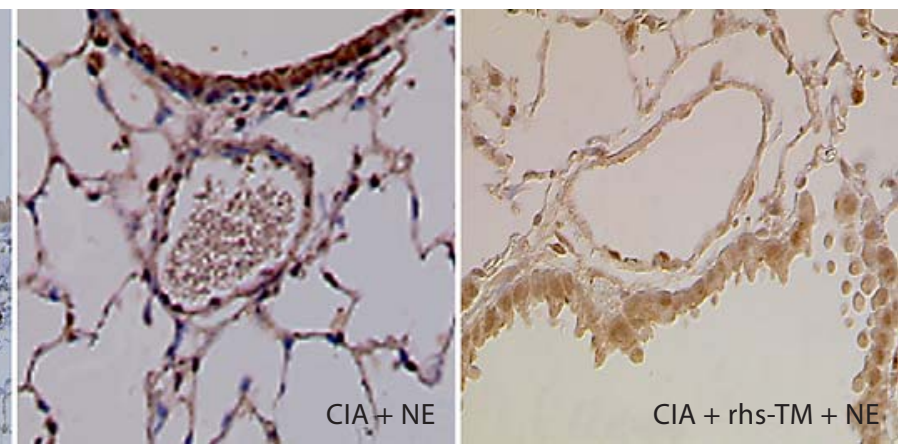

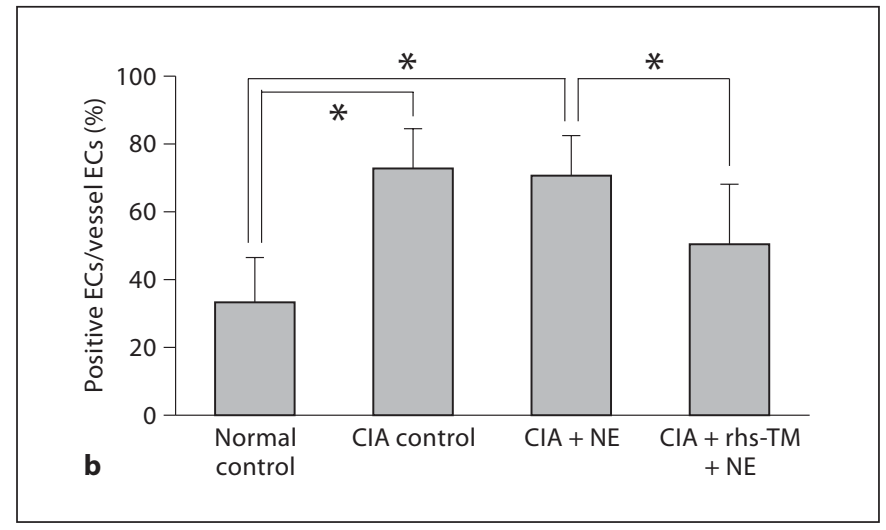

Pathobiology 2008;75:295-305
Fig. 8. Assessment of cell proliferation. a Staining for Ki-67 proliferative cell marker in the lungs from different groups of mice. Original magnification: $\times 200$. b Endothelial cell $(E C)$ proliferation was markedly increased in CIA control and CIA + NE mice and was suppressed in CIA + rhs-TM + NE mice showing the effectiveness of rhs-TM administration. Data are expressed as mean \pm SEM. ${ }^{*} \mathrm{p}<0.05$. 
or inflammatory cytokines like interleukin-6, interleukin-8, granulocyte-macrophage colony-stimulating factor, and inactivation of various coagulation-fibrinolysis factors in vitro [13-15]. One of the important coagulation-fibrinolysis factors is TM that is regarded as the endothelial receptor for the thrombin-catalyzed conversion of protein $\mathrm{C}$ to activated protein C. It acts as a potent membrane-bound anticoagulant cofactor and is regarded as a reliable marker of endothelial cell injury in vitro $[39,40]$.

In our study, the frequency of TUNEL-positive, caspase-3-positive, and $\mathrm{Ki}-67$-positive endothelial cells although increased in CIA + NE mice was not significantly different from CIA control mice. However, neutrophils in BAL fluid and fibrinogen staining were significantly increased in CIA + NE mice. These findings may suggest that NE did not significantly contribute to apoptosis and proliferation of endothelial cells but played an important role in endothelial cell injury in combination with inflammation due to CIA leading to thrombosis.

The plasma level of TAT in the CIA + NE model increased significantly compared to normal controls. This represented a hypercoagulability status. There was no significant difference between the TAT plasma levels of $\mathrm{CIA}+\mathrm{NE}$ and CIA + rhs-TM + NE mice, suggesting that preadministration of rhs-TM had no significant effect on the TAT level. However, its phenotypic reversal effect, i.e. changes from vWF dominance to TM dominance, could facilitate precondition in CIA + rhs-TM + NE mice against developing pulmonary embolism or fibrin deposition in the lung.

To study pulmonary internal environments, we examined BAL fluids. The results revealed that neutrophil differentiation was significantly increased in CIA + NE mice but not in CIA mice, indicating endothelial and epithelial cell injuries. Thus in CIA + NE mice vascular endothelial cells were injured and were in a condition that seemed to be acute respiratory distress syndrome. Double staining for TM and vWF in endothelial cells in both CIA control and CIA + NE mice showed vWF-dominant expression. In general, inflammation by arthritis is known to cause hypercoagulability. Moreover, TM is cleaved to its soluble form by other substances produced during chronic inflammatory responses, immunologic reactions and complement activation in addition to NE in order to protect against hypercoagulopathy. Therefore, in CIA control and CIA + NE mice groups, endothelial cells in the lung changed their phenotypic character from anticoagulant-dominant expression to coagulant-dominant expression. In other words, pulmonary internal environ- ment was rich in vWF instead of TM. But by this change per se PTE could not be developed. Multiple injections of $\mathrm{NE}$ were needed to injure both endothelial and epithelial cells. Fibrinogen was also elevated in CIA control and $\mathrm{CIA}+\mathrm{NE}$ mice and administration of rhs-TM showed reduction in fibrinogen deposition. Haubitz et al. [41] showed that NE increases TF activity that is known as the primary cellular initiator of blood coagulation. TF exposure is a potent prothrombotic trigger that initiates activation of the coagulation cascade, while TM is a potent anticoagulant protein that inhibits the extent of activation. Both TF-neutralizing antibodies and soluble TM are considered effective anticoagulants. Thus, a multifactorial combination was involved in the generation of PTE in our model.

We found that rhs-TM reduced PTE. Administration of rhs-TM to CIA + NE mice revealed a conversion in the phenotype of endothelial cells from vWF-dominant expression to TM-dominant expression, which may contribute to the anticoagulant function. In a previous study, Ikeguchi et al. [16] showed that rhs-TM is a potential novel therapeutic tool for thrombosis. In fact, rhs-TM is a new anticoagulant that was well tolerated in a phase I study in human volunteers [42]. These results were in agreement with our findings. In addition, rhs-TM prevented apoptosis and suppressed proliferation of endothelial cells, which may indicate a synchronized regulation for stabilization of endothelial cell function by diminishing endothelial cell injury.

In conclusion, we developed organized PTE by repeated use of NE in CIA mice. We also showed that rhs-TM reduced PTE. Taken together, our observations suggest that the use of a tourniquet in RA patients should be considered as one of the risk factors for postoperative development of PTE as it may cause NE release. We suggest, therefore, that where possible the use of a tourniquet should be avoided in surgical operations of upper and lower extremities in RA patients.

References

1 Lieberman JR: Venous thromboembolism after total hip arthroplasty; in Callaghan JJ, Rosenberg AG, Rubash HE (eds): The Adult Hip. Philadelphia, Lippincott-Raven, 1998, pp 633-646.

2 Laporte S, Mismetti P, Décousus H, Uresandi F, Otero R, Lobo JL, Monreal M, RIETE Investigators. Clinical predictors for fatal pulmonary embolism in 15,520 patients with venous thromboembolism: findings from the Registro Informatizado de la Fermedad TromboEmbolica venosa (RIETE) Registry. Circulation 2008;117:1711-1716. 
-3 Anderson FA Jr, Wheeler HB, Goldberg RJ, Hosmer DW, Patwardhan NA, Jovanovic B, Forcier A, Dalen JE: A population-based perspective of the hospital incidence and casefatality rates of deep vein thrombosis and pulmonary embolism. The Worcester DVT Study. Arch Intern Med 1991;151:933-938.

4 Haas S: Deep vein thrombosis: beyond the operating table. Orthopedics 2000;23(suppl 6):S629-S632.

-5 Kannan K, Ortmann RA, Kimpel D: Animal models of rheumatoid arthritis and their relevance to human disease. Pathophysiology 2005; $12: 167-181$

6 Day SM, Reeve JL, Myers DD, Fay WP: Murine thrombosis model. Thromb Haemost 2004;92:486-494.

7 Lee JH, Chun YG, Lee IC: Pathogenic role of endothelin 1 in hemodynamic dysfunction in experimental acute pulmonary thromboembolism. Am J Respir Crit Care Med 2001; 164:1282-1287.

-8 Singh I, Burnand KG, Collins M, Luttun A, Collen D, Boelhouwer B, Smith A: Failure of thrombus to resolve in urokinase-type plasminogen activator gene-knockout mice: rescue by normal bone marrow-derived cells. Circulation 2003;107:869-875.

9 Walker FJ, Fay PJ: Regulation of blood coagulation by the protein C system. FASEB J 1992;6:2561-2567.

-10 Seigneur M, Dufourcq P, Conri C, Constans J, Mercie P, Pruvost A, et al: Levels of plasma thrombomodulin are increased in atheromatous arterial disease. Thromb Res 1993; 71:423-431.

11 Kumada T, Dittman WA, Majerus PW: A role for thrombomodulin in the pathogenesis of thrombin-induced thromboembolism in mice. Blood 1988;71:728-733.

$\checkmark 12$ Gomi K, Zushi M, Honda G, Kawahara S, Matsuzaki O, Kanabayashi T, et al: Antithrombotic effect of recombinant human thrombomodulin on thrombin-induced thromboembolism in mice. Blood 1990;75: 1396-1399.

13 Mohri M, Suzuki M, Sugimoto E, Sata M, Yamamoto S, Maruyama I: Effects of recombinant human soluble thrombomodulin (rhs-TM) on clot-induced coagulation in human plasma. Thromb Haemost 1998;80: 925-929.

14 Hasegawa N, Kandra TG, Husari AW, et al: The effects of recombinant human thrombomodulin on endotoxin-induced multiplesystem organ failure in rats. Am J Respir Crit Care Med 1996;153:1831-1837.

15 Uchiba M, Okajima K, Murakami K, Johno M, Mohri M, Okabe H, Takatsuki K: rhs-TM prevents ET-induced increase in pulmonary vascular permeability through protein $\mathrm{C}$ activation. Am J Physiol 1997;273:L889-L894.

16 Ikeguchi H, Maruyama S, Morita Y, et al: Effects of human soluble thrombomodulin on experimental glomerulonephritis. Kidney Int 2002;61:490-501.
17 Mackman N, Brand K, Edgington TS: Lipopolysacharide-mediated transcriptional activation of the human tissue factor gene in THP-1 monocytic cells requires both activator protein 1 and nuclear factor kappa $B$ binding sites. J Exp Med 1991;174:15171526.

18 Taubman MB, Marmur JD, Rosenfield CL, Guha A, Nichtberger S, Nemrson Y: Agonistmediated tissue factor expression in vascular smooth muscle cells: role of calcium mobilization and protein kinase $\mathrm{C}$ activation. J Clin Invest 1993;91:547-552.

19 Rosenberg RD, Aird WC: Vascular-bed-specific hemostasis and hypercoagulable states. N Engl J Med 1999;340:1555-1564

20 Zemanova P, Opatrny K, Opatrna S, Vit L, Sefrna F, Racek J: Tissue factor, its pathway inhibitor, and metabolic disturbances in long-term peritoneal dialysis. Kidney Blood Press Res 2003;26:368-375.

21 Wauke K, Nagashima M, Kato N, Ogawa R, Yoshino S: Comparative study between thromboembolism and total knee arthroplasty with or without tourniquet in rheumatoid arthritis patients. Arch Orthop Trauma Surg 2002;122:442-446.

22 Kinoshita M, Ono S, Mochizuki H: Neutrophils mediate acute lung injury in rabbits: role of neutrophil elastase. Eur Surg Res 2000;32:337-346.

23 Lee WL, Downey GP: Leukocyte elastase physiological functions and role in acute lung injury. Am J Respir Crit Care Med 2001; 164:896-904.

24 Kawabata K, Hagio T, Matsuoka S: The role of neutrophil elastase in acute lung injury. Eur J Pharmacol 2002;451:1-10.

25 Ishikawa N, Oda M, Kawaguchi M, Tsunezuka Y, Watana G: The effects of a specific neutrophil elastase inhibitor (ONO-5046) in pulmonary ischemia-reperfusion injury. Transpl Int 2003;16:341-346.

26 Mukubo Y, Kawamata M: Perioperative hypercoagulability in patients with rheumatoid arthritis: Sonoclot study. J Anesthesiol 2004;18:62-64.

27 Campbell IK, Hamilton JA, Wicks IP: Collagen-induced arthritis in C57BL/6 $\left(\mathrm{H}-2^{\mathrm{b}}\right)$ mice: new insights into an important disease model of rheumatoid arthritis. Eur J Immunol 2000;30:1568-1575.

28 Kobayashi Y, Tagawa N, Muraoka K: Participation of endogenous dehydroepiandrosterone and its sulfate in the pathology of collagen-induced arthritis in mice. Biol Pharm Bull 2003;26:1596-1599.

29 Courtenay JS, Dallman MJ, Dayan AD, et al: Immunization against heterologous type $\alpha$ collagen induced arthritis in mice. Nature 1980;283:666-667.

30 Marty I, Pecalat, Kirdaite G, Salvi R, So A Busso N: Amelioration of collagen-induced arthritis by thrombin inhibition. J Clin Invest 2001;107:631-640.

31 Léon C, Freund M, Ravanat C: Key role of the $\mathrm{P} 2 \mathrm{Y} 1$ receptor in tissue factor-induced thrombin-dependent acute thromboembolism studies in P2Y1-knockout mice and mice treated with a P2Y1 antagonist. Circulation 2001;103:718-723.

-32 Kawanami O, Jin E, Ghazizadeh M, Fujiwara $M$, Jiang L, Nagashima $M$, Shimizu $H$, Takemura T, Ohaki Y, Arai S, Gomibuchi M, Takeda K, Yu ZX, Ferrans VJ: Mosaic-like distribution of endothelial cell antigens in capillaries and juxtaalveolar microvessels in normal human lung. Pathol Int 2000;50: 136-141.

-33 Jin E, Ghazizadeh M, Fujiwara M, Nagashima M, Shimizu H, Ohaki Y, Arai S, Gomibuchi M, Takemura T, Kawanami O: Angiogenesis and phenotypic alteration of alveolar capillary endothelium in areas of neoplastic cell spread in primary lung adenocarcinoma. Pathol Int 2001;51:691-700.

34 Jin E, Fujiwara M, Nagashima M, Shimizu H, Ghazizadeh M, Pan X, Arai S, Ohaki Y, Gomibuchi M, Takemura T, Kawanami O: Aerogenous spread of primary lung adenocarcinoma induces ultrastructural remodelling of the alveolar capillary endothelium. Hum Pathol 2001;32:1050-1058.

35 Renzoni EA, Walsh DA, Salmon M: Interstitial vascularity in fibrosing alveolitis. Am J Respir Crit Care Med 2003;167:438-443.

36 May M, Marx A, Seidenspinner S, Speer CP: Apoptosis and proliferation in lungs of human fetuses exposed to chorioamnionitis. Histopathology 2004;45:283-290.

37 Katsumata S, Nagashima M, Kato K, Tachihara S, Wauke K, Saito S, Jin E, Kawanami O, Ogawa R, Yoshino S: Changes in coagulation-fibrinolysis marker and neutrophil elastase following the use of tourniquet during total knee arthroplasty and the influence of neutrophil elastase on thromboembolism. Acta Anaesthesiol Scand 2005;49:510-516.

38 Okajima K, Harada N, Uchiba M, Mori M: Neutrophil elastase contributes to the development of ischemia-reperfusion-induced liver injury by decreasing endothelial production of prostacyclin in rats. Am J Physiol Gastrointest Liver Physiol 2004;287:G1116G1123.

39 Esmon CT: Molecular events that control the protein-C anticoagulant pathway. Thromb Haemost 1990;70:29-35.

40 Abe H, Okajima K, Okabe H, Takatsuki K, Binder BR: Granulocyte proteases and hydrogen peroxide synergistically inactivate thrombomodulin of endothelial cell in vitro. J Lab Clin Med 1994;123:874-881.

41 Haubitz M, Gerlach M, Kruse HJ, Brunkhorst R: Endothelial tissue factor stimulation by proteinase 3 and elastase. Clin Exp Immunol 2001;126:584-588.

42 Moll S, Lindley C, Pescatore S, Morrison D, Tsuruta K, Mohri M, Serada M, Sata M, Shimizu H, Yamada K, White GC: Phase I study of a novel recombinant human soluble thrombomodulin, ART-123. J Thromb Haemost 2004;2:1745-1751. 